\title{
¿Pertenecen al género de las coplas las traducciones sefardíes de piyutim?*
}

\author{
Elena ROMERo
}

CSIC, Madrid

Podemos establecer el corpus de piyutim -poemas litúrgicos- en judeoespañol en más de ochenta textos: algunos de ellos en versión única y otros abundantemente repetidos; algunos se escribieron originalmente en lengua vernácula, pero la mayoría se han traducido del hebreo, no siendo fenómeno infrecuente el encontrar diversas traducciones de un mismo piyut 1.

Piyutim escritos originalmente en lengua sefardí conocemos desde los mismísimos albores de la literatura sefardí textualmente documentada; baste con recordar los que, como solución de continuidad entre las diferentes etapas de la secuencia narrativa, aparecen en las dos primeras ediciones (Constantinopla 1732 y 1745) de la copla hagiográfica (o poema épico-lírico) de Las hazañas de José de Abraham Toledo 2.

Pero aquí no vamos a ocuparnos de ellos sino de los piyutim traducidos del hebreo y de su conexión con el género poético sefardí de las coplas.

\footnotetext{
* Comunicación presentada al sexto Congreso de la European Association for Jewish Studies (Toledo, 19-23 de jul. de 1998).

1 Véase la caracterización del género en mi libro La creación literaria en lengua sefardi (Madrid 1992) págs. 69-77 y la bibliografía anotada en pág. 80.

2 Vid. al respecto el imprescindible artículo de Edwin SEROUSSI, «La música en las Coplas de Yosef haŝadic de Abraham Toledo (1732)», Sefarad 56 (1966) págs. $377-400$.
} 
Se han traducido al judeoespañol un buen número de los piyutim del oracional hebreo propio del rito sefardí pertenecientes a la liturgia de diario o de las festividades del ciclo litúrgico, resultando estos contrafacta más o menos apegados al original y más o menos poéticos. Recordemos que no todos esos piyutim hebreos tienen una forma claramente poética, sino que en ocasiones se trata de letanías sin medida ni rima, según el estilo clásico del antiguo piyut hebreo.

Aunque su acervo no está ni con mucho estudiado y aun faltando la necesaria base textual fidedigna, sin embargo, a partir de lo parcial y asistemáticamente conocido pueden adelantarse algunos rasgos caracterizadores.

En ocasiones conocemos los nombres de los traductores, pero muchas versiones nos han llegado anónimas, sobre todo en el caso de las difundidas antes de nuestro siglo.

El resultado poético de estas composiciones es variado: las hay que tienen como único rastro de versificación el presentar una estructura formal fruto de la segmentación del texto en frases no poéticas que responden a los versos hebreos y la agrupación de estos en conjuntos que responden a las estrofas del original; en el extremo opuesto están las que ofrecen una estructura poética coincidente en todo o en parte con alguna de las propias y caracterizadoras del género de las coplas. Y entre medias quedan aquellas que o bien presentan un estrofismo ajeno al de las coplas o bien tienen una estructura estrófica compuesta por versos anisosilábicos rimados, que requiere un análisis del estudioso.

Las traducciones van desde versiones serviles hasta recreaciones libres más o menos alejadas del texto original, pasando por traducciones que podríamos denominar «calco light»: que utilizan un léxico perteneciente mayoritariamente a las traducciones calco, pero que flexibilizan la rígida fidelidad sintáctica en construcciones más en consonancia con las de la lengua sefardí.

De un buen número de piyutim en hebreo hay traducciones cuya antigüedad aparece evidenciada por su venerabilidad léxica y otros rasgos lingüísticos; en cambio otros son de épocas recientes (siglos XIX y XX). 
Son poemas destinados a ser cantados en el oficio sinagogal, la mayoría de las veces con las mismas melodías con que se entonan los textos originales. Algunas traducciones de piyutim han alcanzado un cierto grado de tradicionalización a través de su uso litúrgico y de su inclusión en sucesivas ediciones de mahźorim. Y en no pocas pueden advertirse notables diferencias textuales entre las dos tradiciones editoriales más propagadas: la de Viena y la de Salónica.

A estas traducciones al menos semitradicionalizadas han venido a unirse en las últimas generaciones creativas unas nuevas traducciones «libres» (así denominadas a veces) en las que se manifiestan ya todos los rasgos de la lengua sefardí moderna y de la moderna poesía de autor. Por su popularización precisamente en las generaciones de la segunda dispersión sefardí del último siglo, estas recreaciones modernas han venido casi a desplazar las más castizas formulaciones creadas en los tiempos de pleno esplendor de la lengua sefardí clásica.

Por lo que respecta a las coplas, no parece necesario repetir aquí la caracterización ya muy difundida del género ${ }^{3}$. Sólo voy a recordar aquellos de sus rasgos que utilizaré en mi argumentación. Se trata de poemas estróficos, con un estrofismo variado, entre cuyas muchas posibilidades se encuentran también los cuartetos monorrimos y las estrofas zejelescas; en los versos no es imposible el anisosilabismo ${ }^{4}$. Son poemas de autor, pero en un buen número de casos los nombres de sus componedores han caído en el olvido. En su mayoría se han cantado en grupo o al menos el público asistente ha coreado los estribillos; estas repeticiones orales han provocado que haya coplas cuyos textos se han semitradicionalizado. Etcétera.

Hecho este preámbulo voy a centrarme ya en el tema, valiéndome de dos ejemplos de piyutim traducidos al judeoespañol, los que comienzan Im afés y Ahot quetaná.

3 Por tratarse de la última presentación de conjunto, puede verse la incluida en mi libro Creación págs. 141-172.

4 Sobre el estrofismo de las coplas véase mi artículo «Formas estróficas de las coplas sefardíes», en Actas del Primer Coloquio Internacional sobre Poesía Estrófica, Árabe, Hebrea y sus Paralelos Romances (Madrid 1991) págs. 259-278. 


\section{Im afés}

Este piyut, que comienza con la frase «Im afés roba haquén» ('Si se acabó el yacer en el nido'), forma parte de las selihot, oraciones penitenciales de contenido rogatorio que se rezan en los días llamados «temerosos», que van desde el primero del mes de elul hasta Yom kipur.

Se debe a la pluma de Efráyim ben Yiŝhac de Regensburgo (1110-1175) ${ }^{5}$ y del texto hebreo existen diferentes versiones que presentan entre sí algunas variantes textuales.

En lo formal consta de 17 estrofas formadas por cuartetas monorrimas. $\mathrm{Y}$ en cuanto a su contenido, narra el sacrificio de Isaac, para concluir con la esperanza de que el mérito alcanzado por Abraham y su hijo permita que Dios preste oídos a las súplicas de su pueblo.

De este piyut conocemos cinco diferentes versiones en judeoespañol. Dos prosificadas: una anónima, que comienza «Si se atemó yaćedura de el nido» (1885/1892), la cual sigue muy de cerca el texto del original y de cuya edición me ocupé hace ya varios años 6; y otra traducida por Nisim Behar Avraam (1947)7, que comienza «Si se atemó a polvo el nido». Las otras tres traducciones tienen forma poética: la compuesta por Reubén Eliyahu Israel (1910) 8 , que comienza «Si el servicio de los sacrificios fue abandonado»; la atribuida a dos autores, a Hayim Efendi, que fue cantor de Esmirna, y a Eliyá Rodric (1928) 9, que empieza «Si se atemaron piadades del nido»; y la de Yehudá $\breve{S}$.

5 Su nombre queda plasmado en el acróstico de las estrofas 1-16, en las que se lee: «Efráyim bar rab Yiŝhac haźac».

6 Vid. mi artículo «Versiones judeoespañolas de un poema litúrgico hebreo sobre el sacrificio de Isaac», en Homenaje a Pedro Sainz Rodríguez (Madrid 1986) vol. I págs. 441-451.

7 En su Kantes relijyozos de selihot, Ros-Asana $i$ Kipur en cudeo-espanyol (Istanbul 1947) págs. 18-20, en letras latinas.

8 Vio la luz por primera vez en Traducción libre de las poesías hebraicas de Roš hašaná y Kipur (Esmirna 1910) págs. 17-20. De ella recoge una versión oral Isaac Jack Levy en su Sephardic Ballads and Songs in The United States: New Variants and Additions (Tesis: Univ. of Iowa, feb. 1959) núm. 109 págs. 129-130, cantada en Atlanta por Katherina Israel natural de Milas (Rodas).

9 Publicada por primera vez en Los piyutim de los días temerosos (Constantinopla 1928) págs. 29-31. 
I. Levy (1934) 10, que empieza «Meśmo que se destruyó la Caśa santa».

En su momento consideramos coplas las dos primeras traducciones citadas -las de Reubén Eliyahu Israel y de Efendi-Rodricy como tales quedaron incluidas en nuestro libro Bibliografía analitica de ediciones de coplas sefardies (BAECS) ${ }^{11}$; allí las denominábamos respectivamente El merecimiento de Isaac I 12 y II 13 .

E1 primero de los dos textos («Si el servicio de los sacrificios ...») consta de 16 estrofas -falta la 17 del original hebreoformadas por cuartetos monorrimos de versos anisosilábicos; en tanto que el segundo ( $\mathrm{Si}$ se atemaron ...») está formado por 14 estrofas -faltan las 14-17 del original y el autor inventa una nueva que sirve de remate al texto sefardí-, que como en el caso anterior también son cuartetos monorrimos de versos anisosilábicos.

Como muestra de las formulaciones judeoespañolas veamos la estrofa 5 de ambas versiones a la luz del original hebreo. Dicha estrofa corresponde al momento en que Isaac pregunta a su padre por qué no llevan animal alguno que sacrificar y escucha las palabras tranquilizadoras de Abraham; dice así en hebreo:

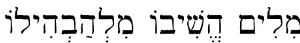

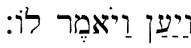

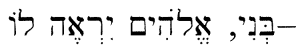

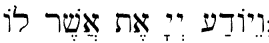

que en El merecimiento de Isaac I de Reubén Eliyahu Israel se traduce por:

10 En su Traduction libera de siertos textos de nuestra liturghia santa (Craiova 1934) págs. 46-48, en caracteres latinos.

11 De Elena Romero, en colaboración con Iacob M. HASSÁn y Leonor CARRACEDO; intr. de I. M. HASSÁN (Madrid 1992).

12 Vid. BAECS núms. 207b, 232b, 242a, 244d y 255b.

13 Vid. BAECS núms. 244a, 248a y 250a. A estas versiones debo añadir ahora la publicada en una hojilla suelta y sin fecha, cuyo encabezamiento dice «Im afés, conponido de Hayim Efendi, cantador afamado de Edirne» y en colofón «Hecho estanpar por mano de se' Nisim Haleví, melamed y meźamer en el c"c de Vidín». 
Entonces su padre por no aturbarlo le respondió a su hijo por contentarlo: -El Dio aprontará el animal por degollarlo; nośotros debemos caminar y esperarlo-;

y en El merecimiento de Isaac II de Efendi o Rodric es:

Dulces hablas le respondió por no aturḅarlo y respondió y dijo a él por bien afalagarlo:

-El carnero, el Dio mo lo va mostrarlo; secreto del santo Dio quén puedrá alcanzarlo.

No puede sin embargo considerarse copla la traducción de Yehudá Šabetay Levy de Im afés a la que antes hemos aludido («Mezmo che se destruio ...»). Consta de 17 estrofas formadas por versos largos de rima $\mathrm{AABB}$, que podíamos describir como pareados emparejados, forma estrófica que no corresponde al género castizo de las coplas, y que sin embargo es relativamente frecuente en la poesía moderna judeoespañola, probablemente por influencia de la métrica francesa. Veamos como ejemplo la estrofa 5 de esta versión, que se publicó en caracteres latinos, cuya grafía mantengo (la acentuación y puntuación es mía):

Estonces su padre por non trublarlo le respondió a su ijo por contentarlo: -Esto se lo deşaremos para el Dio; agora aremos su comando tú y io-.

\section{Ahot quetaná}

El piyut que comienza «Aḥot quetaná tefiloteha» se canta en la oración vespertina de la víspera de Roš hašaná. Lo compuso el cabalista Abraham ben Yiŝhac de Gerona (mediados s. XIII), cuyo nombre aparece en el acróstico, donde se lee «Abraham Haźán, haźac».

En lo formal consta de ocho estrofas: una introductoria de cuatro versos monorrimos con cesura, seguida de otras siete de estructura zejelesca formadas por cinco versos con cesura de 
rima $\mathrm{AAABB}$, el último de los cuales «tijlé šaná vequileloteha» 'acabe el año y sus maldiciones' es igual al que remata la estrofa previa, excepto en la última estrofa que es «tahel šaná ubirjoteha» 'empiece el año y sus bendiciones'. En cuanto al tema, es estrictamente rogatorio: se narran las desgracias de Israel en el exilio y se expresa la esperanza de renovación del pacto con Dios que permitirá al pueblo regresar a Sión.

Conocemos cinco traducciones diferentes al judeoespañol: una anónima ${ }^{14}$, que empieza «El rey Šelomó llamó a la nación judía hermana chica demanda en sus oraciones». Y otras cuatro compuestas respectivamente por los siguientes autores: Reubén Eliyahu Yisrael (1910) ${ }^{15}$, que se inicia «La nación judía recita oraciones»; Yehudá Gabay (1928) ${ }^{16}$, que comienza «La chica hermana entre las naciones»; León Gabay (1930) 17, cuyo inicio es «La chica hermana medita con sus rogativas»; y Yehudá Šabetay. I. Levy (1934) ${ }^{18}$, que empieza «La ermana cica (La nation judia) sus orasiones».

Por su estrofismo no regular y por su rima escasa, se puede considerar como no perteneciente al género de las coplas la traducción anónima arriba citada, que consta de ocho estrofas mayoritariamente de cuatro versos -excepto la tercera de 3 y la octava de 5-, con tendencia a la rima monorrima. Por las mismas razones que antes he señalado al ocuparme de Im afés, tampoco es copla la versión de León Gabay, formada por ocho estrofas de cuatro versos anisosilábicos de rima $\mathrm{AABB}$ más uno de vuelta, igual en todas las estrofas menos en la última.

En su momento no tuvimos dificultad en considerar copla el texto de Reubén Eliyahu Yisrael, que se incluyó en nuestro Catálogo antes citado con el título de La hermana pequeña ${ }^{19}$.

Consta esta versión de ocho estrofas, cuya estructura estrófica se aproxima a la del piyut hebreo original: una primera estrofa de cuatro versos monorrimos con cesura, seguida de

14 En Tefilot ufiyutim leRoš hašaná ulYom haKipurim (Sofía s.a.) págs. 1-2.

15 En su Traducción liḅre (vid. nota 7) págs. 5-6.

16 En Los piyutim de los días temerośos (Constantinopla 1928) págs. 9-10.

17 En Poeśías religioiośas de las santas fiestas (Constantinopla 1930) págs. 29-31.

18 Vid. nota 9, págs. 50-51.

19 Vid. BAECS núms. 107a, 232a y 255a. 
otras siete de rima zejelesca formadas por cinco versos todos ellos con cesura de rima $\mathrm{AAABB}$, siendo el último verso «Termine la añada y sus maldiciones»-que repite el último de la estrofa inicial-igual en todas las estrofas, excepto en la última, que se cambia en «Empece la añada y sus bendiciones».

Veamos como ejemplo la última estrofa que en el texto hebreo dice:

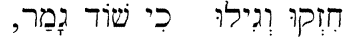

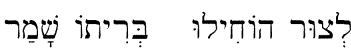

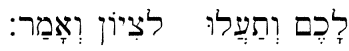

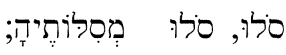

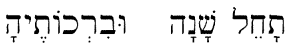

y que en la traducción libre judeoespañola de Reubén Eliyahu Israel se convierte en:

Estadvos tranqüilos, tened esperanza; no olvidó el Eterno su vieja alianza.

A Ŝiyón subiréš con su ordenanza.

Él realiźará vuestras aspiraciones.

Empece la añada y sus bendiciones.

Hasta aquí todo queda bastante claro en cuanto a la inclusión de los textos comentados en el género de las coplas. Pero el problema lo plantean los otros dos textos judeoespañoles: el de Yehudá Gabay y el de Yehudá Šabetay Levy, que no se incluyeron en nuestro Catálogo antes citado.

Constan ambos de las ocho consabidas estrofas, que en el caso del texto de Yehudá Gabay son cuartetos monorrimos de versos anisosilábicos, excepto la última a la que se han añadido dos versos, que quizá en la intención del autor deberían repetirse tras cada estrofa. Veamos como ejemplo esta última:

Esforzadvos, alegradvos, que la desdicha fue terminada. Esperad al Dio que su prometa ya es acordada, dićiéndovos subir a Siyón en esta añada.

¡Todos en una enderechad la calzada!

Se termine la añada 5688 [= 1928] y sus malhores; empece la añada 5689 [= 1929] con satisfacciones. 
Por su parte el poema de Yehudá Šabetay Levy, que mantiene en parte la artificiosidad estructural del texto hebreo original, consta de una primera estrofa que es un cuarteto monorrimo, seguida de otras siete de cinco versos, formados por un cuarteto monorrimo más un último verso - «Se termine el anio giunto sus maldisiones»- igual al que remata la estrofa primera, excepto en la última que se cambia en «Empese el anio nuevo con todas sus bendisiones». Veamos como ejemplo esta última estrofa completa (el texto está en caracteres latinos; mantengo la grafía, pero son mías la acentuación y la puntuación):

Encorajadvos con alegría, che fin de la dezgrasia va [arivar.

Esperad en el Dio che su aliansa va renovar; vuestro dezeo de partir a Sion se va realizar. Empesad el terreno aprontar y aranjar.

Empese el anio nuevo con todas sus bendisiones.

La cuestión ahora es: estos dos poemas ¿debemos o no considerarlos coplas? Para llegar a una conclusión debemos analizarlos a la luz de algunas de las características que hemos señalado como propias de las coplas.

En ambos poemas concurren varios de tales elementos caracterizadores: son poemas estróficos con un estrofismo posible dentro del género; son textos para ser cantados o al menos coreados sus estribillos; su contenido lírico permite establecer una secuencia de ideas, y aunque no sea más que por tener un refrendo previo, no podrían pasar sin quedar dañados por el proceso de intercambiabilidad u omisión de estrofas típico del cancionero; son producto de la creatividad en este caso traductora de un autor, conozcamos o no su nombre. Y por último su anisosilabismo no es óbice para excluirlos del grupo: muy castizas coplas lo tienen, como las de Šabu'ot en tercetos y algunas de Purim en cuartetos; y tal rasgo no impidió que nosotros mismos consideráramos coplas los textos de Im afés antes comentados. 
Queda por tanto entonar un mea culpa muy científico y pensar que nos equivocamos al dejar fuera de nuestro Catálogo estos dos poemas.

Item más. Para el futuro habrá que tener en cuenta otras dos cuestiones que afectan a la poesía litúrgica traducida al judeoespañol. En primer lugar, que a la hora de considerar uno de esos textos dentro del género de las coplas sefardíes no es determinante cuál sea el esquema del texto hebreo del que se parte. Y en segundo lugar, no debe olvidarse que no se trata de textos de libre creación, sino que el traductor se encuentra cohartado por un texto predeterminado, y que, dado lo sintético de la lengua hebrea, la medida del verso resultante, traducido a una lengua indoeuropea, será siempre de mayor longitud que la del original hebreo. Sólo el buen estro poético del traductor le hará llegar a resultados rímicos, rítmicos y textuales satisfactorios.

Como conclusión cabe añadir que el corpus de piyutim en lengua sefardí originales o traducidos del hebreo que nos han llegado impresos está hoy bastante precisado. Pero, al modo del que se ha establecido para las coplas, falta por establecer un repertorio de todos los textos conservados, a los que habrá que añadir los manuscritos y transmitidos por tradición oral; falta por agruparlos en familias textuales y tipográficas; y a partir de ahí, falta por fijar los textos literarios en ediciones filológicas, que tengan en cuenta, por supuesto, los originales en lengua hebrea cuando los haya.

\section{RESUMEN}

Contamos con un amplio corpus de piyutim en judeoespañol, la mayoría de los cuales se ha traducido del hebreo. En el presente artículo se examinan las características que deben presentar tales textos para ser integrados en el género de las coplas. El análisis se lleva a cabo a partir de las versiones judeoespañolas de los piyutim Im afés y Ahot quetaná.

\section{SUMMARY}

We have a extensive collection of piyyutim written in Judeo-Spanish, most of them translated from Hebrew. In this article, I analyze the characteristics that these texts should have in order to be considered as coplas. The analysis is based on the JudeoSpanish versions of the piyyutim Im afes and Ahot quetaná. 